\title{
Clinical Spectrum of Oral Secondary Syphilis in HIV-Infected Patients
}

\author{
Velia Ramírez-Amador, ${ }^{1}$ Gabriela Anaya-Saavedra, ${ }^{1}$ Brenda Crabtree-Ramírez, ${ }^{2}$ \\ Lilly Esquivel-Pedraza, ${ }^{3}$ Marcela Saeb-Lima, ${ }^{4}$ and Juan Sierra-Madero ${ }^{2}$ \\ ${ }^{1}$ Departamento de Atención a la Salud, Universidad Autónoma Metropolitana, 04960 Ciudad de México, Mexico \\ ${ }^{2}$ Clínica de VIH/SIDA, Departamento de Infectología, Instituto Nacional de Ciencias Médicas y Nutrición "Salvador Zubirán", \\ 14000 Ciudad de México, Mexico \\ ${ }^{3}$ Departamento de Dermatología, Instituto Nacional de Ciencias Médicas y Nutrición "Salvador Zubirán", \\ 14000 Ciudad de México, Mexico \\ ${ }^{4}$ Departamento de Patología, Instituto Nacional de Ciencias Médicas y Nutrición “Salvador Zubirán”, 14000 Ciudad de México, Mexico
}

Correspondence should be addressed to Juan Sierra-Madero; jsmadero@yahoo.com

Received 4 September 2012; Accepted 25 November 2012

Academic Editor: Bluma G. Brenner

Copyright (C) 2013 Velia Ramírez-Amador et al. This is an open access article distributed under the Creative Commons Attribution License, which permits unrestricted use, distribution, and reproduction in any medium, provided the original work is properly cited.

Background. Oral lesions may constitute the first clinical manifestation in secondary syphilis, but detailed descriptions in HIVinfected individuals are scarce. Objective. To describe the clinical characteristics of oral secondary syphilis in HIV-infected patients and its relevance in the early diagnosis of syphilis. Methods. Twenty HIV/AIDS adult subjects with oral secondary syphilis lesions presenting at two HIV/AIDS referral centers in Mexico City (2003-2011) are described. An oral examination was performed by specialists in oral pathology and medicine; when possible, a punch biopsy was done, and Warthin-Starry stain and immunohistochemistry were completed. Intraoral herpes virus infection and erythematous candidosis were ruled out by cytological analysis. Diagnosis of oral syphilis was confirmed with positive nontreponemal test (VDRL), and, if possible, fluorescent treponemal antibody test. Results. Twenty male patients (median age 31.5, 21-59 years) with oral secondary syphilis lesions were included. Oral lesions were the first clinical sign of syphilis in 16 (80\%) cases. Mucous patch was the most common oral manifestation (17, 85.5\%), followed by shallow ulcers $(2,10 \%)$ and macular lesions $(1,5 \%)$. Conclusions. Due to the recent rise in HIV-syphilis coinfection, dental and medical practitioners should consider secondary syphilis in the differential diagnosis of oral lesions, particularly in HIV-infected patients.

\section{Background}

In the USA, since 2001 a resurgence in syphilis incidence, especially among males who have sex with men (MSM), has been observed [1]. By 2004, more than a half of new cases reported of primary and secondary syphilis were estimated to occur in MSM, with a high rate of HIV coinfection [2, 3]. During 2007-2008, the total number of cases of syphilis reported to the CDC increased $13.1 \%$ [4].

The increasing incidence of syphilis reported in many studies in the last decade, especially among MSM, is clearly a marker for higher risk behavior in this population and raises concerns for a parallel increase in HIV transmission [5-8].
It has been suggested that HIV infection modifies the clinical presentation of syphilis with greater organ involvement, atypical and florid skin rashes, and more rapid progression to neurosyphilis [9-12]; consequently, the diagnosis of syphilis in HIV-infected individuals represents a challenge for care providers. A careful sexual exposure history, recognition of clinical signs and symptoms, and interpretation of diagnostic testing are crucial in this context [13].

Detailed descriptions of oral manifestations of secondary syphilis in HIV-infected individuals are scarce in the scientific literature [14-19], in contrast with several reports in non-HIV-infected individuals [19-34]. Secondary syphilis 
may mimic other oral lesions such as nonspecific oral ulcerations, oral candidiasis, erythema multiforme, hairy leukoplakia, lichen planus, lupus erythematosus, erythroleukoplakia, and squamous cell carcinoma in both HIV and non$\mathrm{HIV}$-infected patients [14-34]. Moreover, because of the wide spectrum of oral clinical manifestations occurring in $\mathrm{HIV}$-infected individuals, secondary syphilis in the mouth may be difficult to identify if not suspected by the clinician.

Considering that the incidence of syphilis is increasing in most countries, particularly in HIV-infected individuals [9] and that oral lesions may constitute the first or most florid clinical manifestation of the disease, the aim of the present case series is to describe the clinical spectrum of oral secondary syphilis in HIV-infected patients and its relevance in the early diagnosis of systemic syphilis.

\section{Material and Methods}

We report a series of 20 consecutive adult subjects with confirmed HIV infection who presented oral secondary syphilis lesions. Patients attended during the period from 2003 to 2011 two HIV/AIDS referral centers in Mexico City: the Instituto Nacional de Ciencias Médicas y Nutrición Salvador Zubirán (INCMNSZ), a third level hospital, and the Clínica Especializada Condesa (CEC), a primary care center dedicated to the health care of HIV/AIDS patients who do not have social security. During the study period, between both institutions, approximately 2,000 active patients were seen.

Specialists in oral pathology and medicine, at the same AIDS clinic visit in both referral centers, consecutively evaluated all HIV-infected patients. During these visits, a structured oral examination was conducted by two of the authors (V. R.-Amador and G. A.-Saavedra). Syphilis-related oral lesions were classified according to previous criteria $[35,36]$ as follows.

(i) Macular lesions: flat-to-slightly raised, firm, red lesions with particular predilection of the hard palate.

(ii) Papular lesions: red, raised, firm round nodules with a grey center that may ulcerate, usually located on the buccal mucosa or commissures.

(iii) Mucous patches: slightly raised and covered by a grayish, white pseudomembrane, surrounded by erythema. Lesions appear mainly on the soft palate and pillars, tongue, and vestibular mucosa.

(iv) Shallow ulcers: oval erosions or shallow ulcers of about one $\mathrm{cm}$ in diameter, covered by a grey mucoid exudate with an erythematous border.

In order to rule out other oral lesions, lesions suspected as oral syphilis were further evaluated with cytological smear. In macular and papular lesions, it was necessary to consider in the differential diagnosis oral candidosis (OC), particularly the erythematous type. Thus, a cytological smear was taken, and OC was excluded by the absence of Candida sp. in periodic acid Schiff (PAS) stained smears and/or the lack of an antifungal treatment response.

Likewise, in cases of shallow ulcerations located on keratinized oral mucosa, the diagnosis of intraepithelial human herpesvirus infection was ruled out by the absence of virusinfected cells in cytologic smears stained with Papanicolaou, and/or a lack of clinical response to systemic antiviral therapy with acyclovir.

A punch biopsy from oral lesions was performed in six patients who gave their consent to biopsy. For hematoxylin and eosin (H\&E) stain, $5 \mu \mathrm{m}$ sections were cut from formalin-fixed and paraffin-embedded tissue samples. The silver nitrate-based staining method (Warthin-Starry) was used to identify spirochetes.

Immunohistochemistry was performed using a standard avidin-biotin peroxidase complex technique. Sections were stained with a primary polyclonal antibody against Treponema pallidum; antigen-binding sites were visualized through the peroxidase system (Biocare Medical, 4040 Pike Lane, Concord, CA 94520, USA, rabbit polyclonal CAT CP 135B).

In all patients diagnosis of syphilis was confirmed with a positive nontreponemal test at any titer (Venereal Disease Research Laboratory (VDRL) and if possible, a confirmatory fluorescent treponemal antibody test (FTA-ABS).

At diagnosis, medical records were reviewed for information about demographic and clinical characteristics which included risk behavior for HIV transmission, clinical stage [37], tobacco and alcohol use, $\mathrm{CD}^{+}$lymphocyte counts, plasma HIV-RNA level, and current antiretroviral therapy.

Description of variables was done using the Statistical Program for Social Sciences (SPSS) package, with a $95 \%$ confidence level. The prevalence of clinical and laboratory characteristics in patients was reported as percentages.

\section{Results}

Twenty male adult patients, median age of 31.5 (range 21-59) years with oral secondary syphilis lesions, were identified during the study period, 10 at the AIDS Clinic of the INCMNSZ and 10 at the CEC. The clinical characteristics are shown in Table 1; all patients were MSM, of whom 14 (70\%) were receiving HAART, with a median time of use of 32.5 (1-134) months. Of the six patients without HAART, five were naive to antiretrovirals and one had discontinued HAART because of intolerance. The 20 cases were confirmed with positive serologic tests (VDRL in all, FTA-ABS in 15). It is important to mention that CEC is a free governmental HIV/AIDS clinic, so, because of financial issues, FTA-ABS was not performed in five patients; however, in three of them, besides a positive VDRL result, a biopsy led us to confirm the diagnosis. In the other two patients, in addition to a positive VDRL test, the clinical picture was characterized by oral mucous patches which is considered the most typical oral manifestation of secondary syphilis.

In $16(80 \%)$ cases, oral lesions were either the first or most florid clinical sign that led to the diagnosis of secondary syphilis. In the remaining four patients (20\%), oral manifestations were part of a systemic clinical picture already diagnosed as secondary syphilis by the treating clinician. 
TABLE 1: Clinical characteristics in 20 patients with oral syphilis.

\begin{tabular}{|c|c|}
\hline Characteristics & $n(\%)$ \\
\hline AIDS $^{\mathrm{a}}$ & $10(50.0)$ \\
\hline On HAART & $14(70.0)$ \\
\hline Tobacco consumption $(n=19)$ & $6(31.6)$ \\
\hline Alcohol consumption $(n=19)$ & $4(21.1)$ \\
\hline \multicolumn{2}{|l|}{ Main type of lesion } \\
\hline Mucous patches & $17(85.5)$ \\
\hline Shallow ulcers & $2(10.0)$ \\
\hline Macular lesions & $1(5.0)$ \\
\hline \multicolumn{2}{|l|}{ Oral site of main lesion ${ }^{\mathrm{b}}$} \\
\hline Soft palate-pillars & $8(40.0)$ \\
\hline Hard palate & $3(15.0)$ \\
\hline Tongue & $3(15.0)$ \\
\hline Hard-soft palate-pillars & $2(10.0)$ \\
\hline Hard-soft palate-tongue & $1(5.0)$ \\
\hline Hard-soft palate-tongue-buccal mucosa & $1(5.0)$ \\
\hline Upper labial mucosa & $1(5.0)$ \\
\hline Gingiva & $1(5.0)$ \\
\hline \multicolumn{2}{|l|}{ Minor type of lesion $(n=10)$} \\
\hline Papular lesions & $4(40.0)$ \\
\hline Macular lesions & $4(40.0)$ \\
\hline Shallow ulcers & $2(20.0)$ \\
\hline \multicolumn{2}{|l|}{ Oral site of minor lesion $(n=10)$} \\
\hline Tongue & $5(50.0)$ \\
\hline Hard palate & $3(30.0)$ \\
\hline Gingiva/labial mucosa & $1(10.0)$ \\
\hline Soft palate & $1(10.0)$ \\
\hline $\begin{array}{l}\text { Median antiretroviral use (range) months } \\
(n=14)\end{array}$ & $32.5(1-134)$ \\
\hline $\begin{array}{l}\text { With undetectable viral load (<399 copies/mL) } \\
(n=19)\end{array}$ & $10(52.6)$ \\
\hline $\begin{array}{l}\text { Current median } \mathrm{CD}^{+} \text {count (range) cells } / \mu \mathrm{L} \\
(n=19)\end{array}$ & $372(44-734)$ \\
\hline
\end{tabular}

Eleven of the 20 patients (55\%) had mucocutaneous involvement documented in the medical records. Skin manifestations included disseminated maculopapular rash $(n=5)$, hyper pigmented macules/erythematous plaques on palms and soles $(n=3)$, eyebrows/eyelashes alopecia $(n=2)$, and scalp alopecia (1).

The most common clinical manifestation of oral secondary syphilis was mucous patch in 17 cases $(85.5 \%)$, the soft palate and pillars being the most frequent sites . Mucous patches appeared as white slightly raised plaques on an erythematous base with a serpentine and white/reddish well defined outline (Figure 1). Two patients presented shallow ulcers (10\%), and, in one (5\%), macular lesions were the most florid oral sign.
Ten (50\%) of the 20 patients showed more than one type of syphilis-related oral lesion, concurrent mucous patches and papular lesions being the most frequent combination in four patients, followed by mucous patches and macular lesions in three, and shallow ulcers joint with mucous patches in two and with macular lesions in one (Table 2).

We found four cases (20\%) of papular syphilitic lesions in our population, all accompanied with mucous patches and located on dorsal tongue. Macular syphilitic lesions were identified on soft and hard palate (3), dorsum of tongue (1), and labial mucosa (1). In papular and macular cases, the clinical presentation of the oral lesions mimicked erythematous candidosis (Figure 2(a)); the absence of Candida sp. hyphae in the PAS smear, and the lack of response to topical or systemic antifungal treatment, allowed us to rule out erythematous candidosis.

One case of mucous patch on the lateral portion of the tongue resembled hairy leukoplakia (Figure 2(b)), and in another one, lesions in both sides of the tongue seemed lichen planus. In both cases a biopsy was taken and based in the histopathological features; the final diagnosis of oral syphilis was confirmed. In the patients who presented shallow ulcers on the palate (cases 1 and 13), the diagnosis of intraoral herpesvirus infection was ruled out as described in the Material and Methods section (Figure 3).

A biopsy of the oral lesions was taken in six patients who agreed with the procedure; biopsies were processed and stained with $\mathrm{H} \& \mathrm{E}$ and the silver nitrate-based staining method (Warthin-Starry). Microscopically, the lamina propria showed a diffuse (four out of six cases) and a perivascular (three out of six) lymphoplasmacytic inflammatory infiltrate. Occasional eosinophils and neutrophils were also present within the infiltrate and in the epithelium, forming microabscesses. In one case an interface lichenoid pattern was seen. The six oral biopsies examined showed psoriasiform and spongiotic changes in the epithelium; only in one of these cases, a pseudoepitheliomatous hyperplasia was present. Obliteration of the vessels was evident in all cases. WarthinStarry stain detected spirochetes in the epithelium in two of the six biopsies. Immunohistochemistry for T. pallidum revealed numerous spirochetes within keratinocytes, free in the stroma of the lamina propria and within the vessel walls in examined biopsies (Figure 4).

\section{Discussion}

In this paper we report twenty cases of oral secondary syphilis in HIV-infected patients evaluated in two AIDS referral centers in Mexico City, from 2003 to 2011. In most of these cases $(80 \%)$ the oral lesions were the key clinical finding that led to the diagnosis of secondary syphilis; in the remaining cases, oral findings were additional clinical signs to a wellestablished clinical picture.

All cases in this series were males who have sex with men, as it has been stated by several authors in most countries, who have found in recent years an increase in syphilis among MSM [38-42]. In addition, almost half of our patients were 


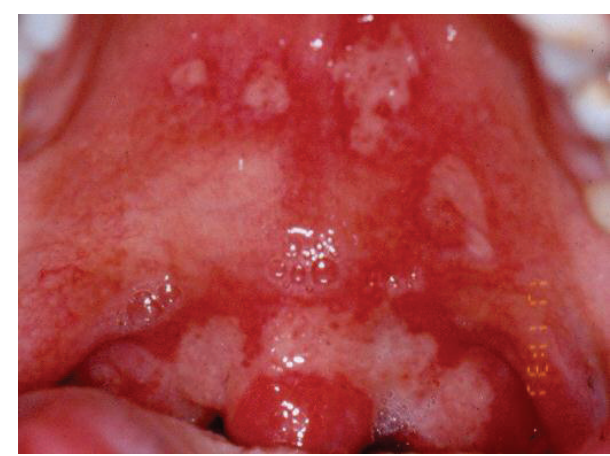

(a)

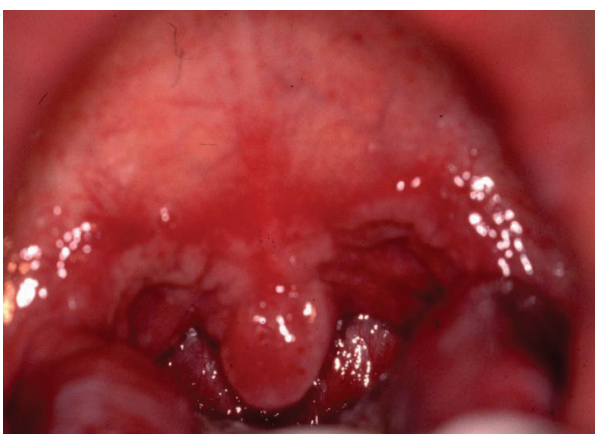

(c)

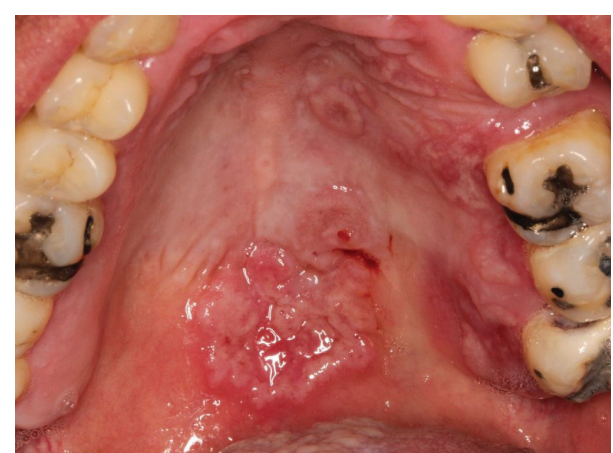

(b)

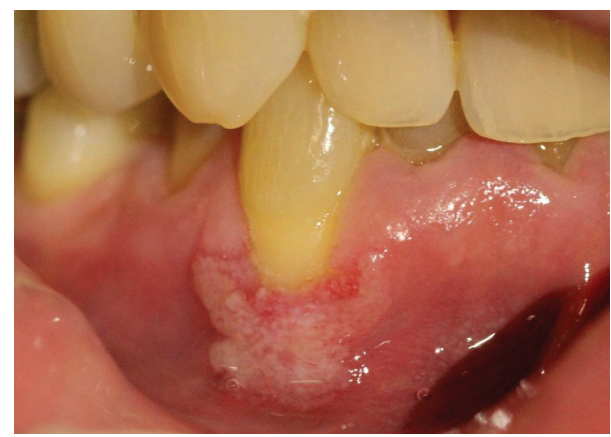

(d)

FIGURE 1: Oral secondary syphilis. White slightly raised plaques with a serpentine and white/reddish well-defined outline, located on hard, soft palate, pillars $(\mathrm{a}-\mathrm{c})$, and gingiva $(\mathrm{d})$.

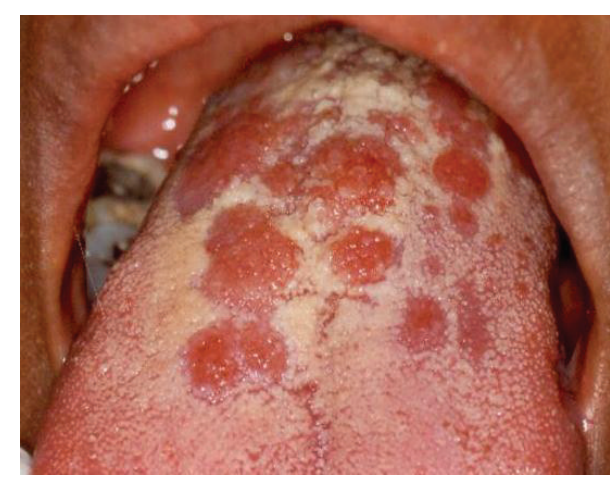

(a)

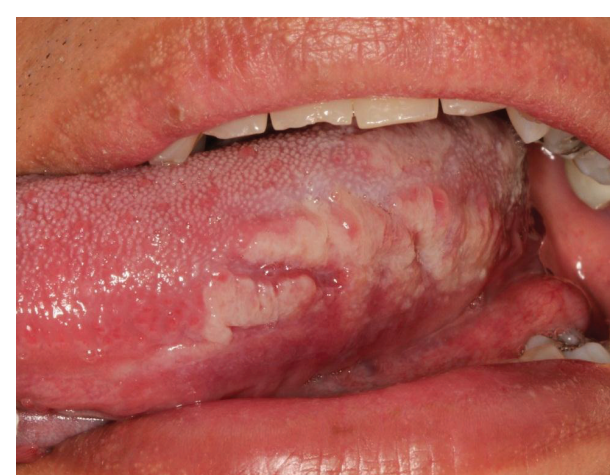

(b)

Figure 2: Oral secondary syphilis. Papular lesions on the dorsum of the tongue mimicking erythematous candidosis (a), mucous patches, hairy leukoplakia-like, on the lateral side of the tongue (b).

young, less than 30 years (45\%), in agreement with previous reports $[39,42]$.

In relation with $\mathrm{CD} 4^{+}$cell levels, it was found that only $7(36.8 \%)$ of 19 patients had less than 350 cells $/ \mathrm{mm}^{3}$ and 6 (30\%) had a VL higher than $4 \log _{10}$ copies/mL at the time of syphilis diagnosis. Different studies in HIV-infected patients with syphilis [10,43-47] have reported a transient decrease in $\mathrm{CD}^{+}$cell count and an increase in VL.

It is important to highlight that during the study period no cases of oral primary or tertiary syphilis were observed. As it has been informed in HIV-infected patients $[9,11,12]$, a higher rate of secondary syphilis is a common clinical finding; oral lesions are usually seen in secondary disease in patients with HIV [12].

Interestingly, even though the rate of HIV-syphilis coinfection has increased in the recent years [13], reports of oral manifestations of syphilis in HIV-infected patients are scarce [14-19, 48, 49]. In contrast, several reports have described oral lesions in non-HIV individuals [19-34].

Regardless of HIV status, the best recognized and characterized oral manifestation of secondary syphilis is the mucous patch, as shown in this case series in which $85.5 \%$ of the 
TABLE 2: Clinical characteristics of 20 patients with oral secondary syphilis.

\begin{tabular}{|c|c|c|c|c|c|c|c|}
\hline ID & Clinical stage $\mathrm{a}^{\mathrm{a}}$ & $\begin{array}{l}\text { Current VL } \\
\text { (copies/mL) }\end{array}$ & $\begin{array}{c}\text { Current CD4 } \\
(\mathrm{cel} / \mu \mathrm{L}) \\
\end{array}$ & Oral lesion & Site & VDRL dilution & FTA-ABS \\
\hline 1 & B2 & 6,310 & 378 & $\begin{array}{l}\text { Shallow ulcer } \\
\text { Macular lesion }\end{array}$ & $\begin{array}{c}\text { Hard palate } \\
\text { Gingiva, labial mucosa }\end{array}$ & $1: 16$ & ++++ \\
\hline 2 & $\mathrm{C} 3$ & UND & 202 & Mucous patches & Hard palate & $1: 8$ & ++ \\
\hline 3 & $\mathrm{C} 1$ & NA & NA & Mucous patches & Soft palate-pillars & $1: 32$ & ++++ \\
\hline 4 & $\mathrm{C} 3$ & 5,470 & 217 & $\begin{array}{l}\text { Mucous patches } \\
\text { Papular lesion }\end{array}$ & $\begin{array}{l}\text { Soft palate-pillars } \\
\text { Dorsal tongue }\end{array}$ & $1: 256$ & +++ \\
\hline 5 & $\mathrm{~A} 3$ & 56,500 & 168 & Mucous patches & Soft palate-pillars & $1: 128$ & +++ \\
\hline 6 & $\mathrm{~A} 2$ & 100,000 & 239 & $\begin{array}{l}\text { Mucous patches } \\
\text { Papular lesion }\end{array}$ & $\begin{array}{l}\text { Soft palate-pillars } \\
\text { Dorsal tongue }\end{array}$ & $1: 128$ & +++ \\
\hline 7 & $\mathrm{~A} 1$ & 9,656 & 681 & Shallow ulcers & Upper labial mucosa & $1: 32$ & NA \\
\hline 8 & B3 & UND & 458 & Mucous patches & Soft palate-pillars & $1: 512$ & +++ \\
\hline 9 & $\mathrm{C} 3$ & 239,146 & 44 & Macular lesion & Dorsal lingual & $1: 2$ & +++ \\
\hline 10 & $\mathrm{C} 3$ & UND & 372 & $\begin{array}{l}\text { Mucous patches } \\
\text { Shallow ulcers }\end{array}$ & $\begin{array}{l}\text { Soft palate-pillars } \\
\text { Tongue }\end{array}$ & $1: 128$ & +++ \\
\hline 11 & $\mathrm{~A} 1$ & 47,011 & 603 & $\begin{array}{l}\text { Mucous patches } \\
\text { Macular lesion }\end{array}$ & $\begin{array}{l}\text { Hard palate } \\
\text { Hard palate }\end{array}$ & $1: 2$ & + \\
\hline 12 & $\mathrm{~A} 1$ & 13,259 & 648 & $\begin{array}{l}\text { Mucous patches } \\
\text { Papular lesion }\end{array}$ & $\begin{array}{c}\text { Hard-soft palate-pillars } \\
\text { Tongue }\end{array}$ & $1: 4$ & + \\
\hline 13 & $\mathrm{C} 2$ & UND & 715 & $\begin{array}{l}\text { Mucous patches } \\
\text { Shallow ulcers }\end{array}$ & $\begin{array}{l}\text { Gingiva } \\
\text { Hard palate }\end{array}$ & $1: 64$ & +++ \\
\hline 14 & $\mathrm{C} 2$ & UND & 360 & Mucous patches & Hard-soft palate-tongue & $1: 32$ & NA \\
\hline 15 & $\mathrm{C} 3$ & UND & 187 & $\begin{array}{l}\text { Mucous patches } \\
\text { Papular lesion }\end{array}$ & $\begin{array}{l}\text { Soft palate-pillars } \\
\text { Dorsal tongue }\end{array}$ & $1: 128$ & +++ \\
\hline 16 & $\mathrm{C} 3$ & UND & 348 & $\begin{array}{l}\text { Mucous patches } \\
\text { Macular lesion }\end{array}$ & $\begin{array}{c}\text { Soft palate-pillars, tongue } \\
\text { Hard palate }\end{array}$ & $1: 32$ & NA \\
\hline 17 & B3 & UND & 370 & Mucous patches & Lateral sides of tongue & $1: 32$ & NA \\
\hline 18 & $\mathrm{C} 3$ & UND & 392 & Mucous patches & Soft palate-pillars & $1: 32$ & NA \\
\hline 19 & $\mathrm{~A} 1$ & UND & 734 & Mucous patches & Hard-soft palate-pillars & $1: 64$ & +++ \\
\hline 20 & A1 & 205,000 & 532 & $\begin{array}{l}\text { Mucous patches } \\
\text { Macular lesion }\end{array}$ & $\begin{array}{c}\text { Lateral tongue } \\
\text { Soft palate }\end{array}$ & $1: 64$ & ++ \\
\hline
\end{tabular}

ID: identification, a according to the CDC revised surveillance case definitions [37] , VL: viral load, VDRL: venereal disease research laboratory, FTA-ABS: fluorescent treponemal antibody absorbed, UND: undetectable, NA: not available.

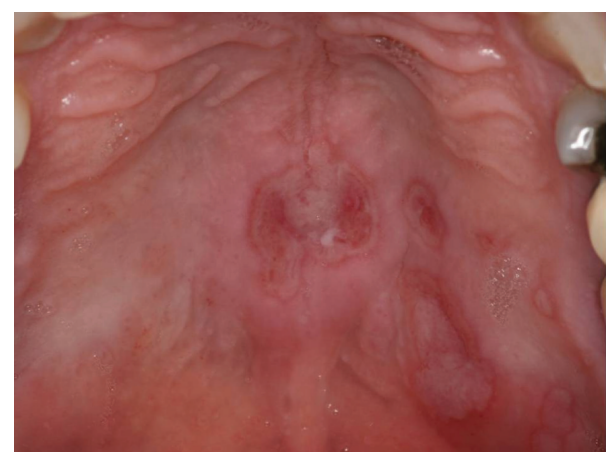

FIGURE 3: Oral secondary syphilis. Shallow ulcers on the hard palate mimicking intraoral herpes virus infection.

patients showed the typical slightly raised plaques, mainly located on the palate and soft pillars, which are the common sites described $[35,50]$.
Although the clinical criteria for mucous patches lesions usually involve slightly elevated plaques and superficial ulcers covered by a gray or white pseudomembrane (shallow ulcers) [36], we decided to consider shallow ulcers separately from mucous patches due to two main reasons: the frequent finding of isolated shallow ulcers in our population and the remarkable clinical differences between both types of lesions. Thus, a clinical description for shallow ulcers was added and defined independently from mucous patches as oval erosions or shallow ulcers of about $1 \mathrm{~cm}$ in diameter, covered by a grey mucous exudate with an erythematous border.

In addition to mucous patches $[14,17,48]$, shallow ulcers $[14,17]$, papular $[15,16]$ and macular lesions [19] have also been described in HIV-infected patients with oral syphilis. As described by Ortega et al. [14,17] we found four cases of shallow ulcers on palate, tongue, and labial mucosa. Also, as other authors have described [19,36], palate was the favorite site for macular syphilis lesions that were found in five cases. 


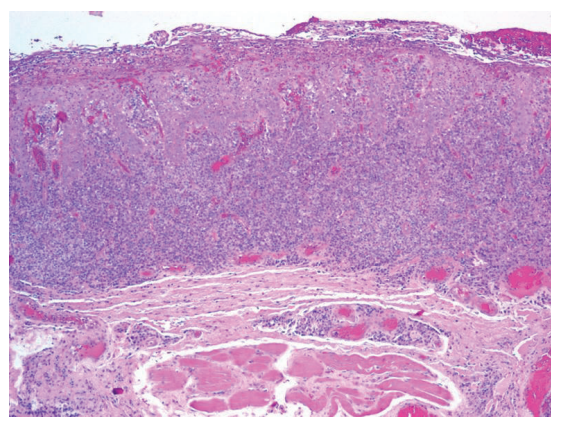

(a)

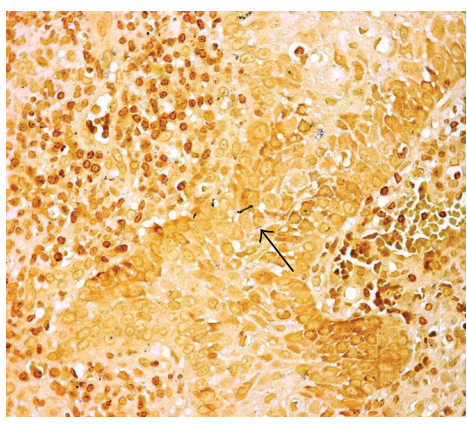

(b)

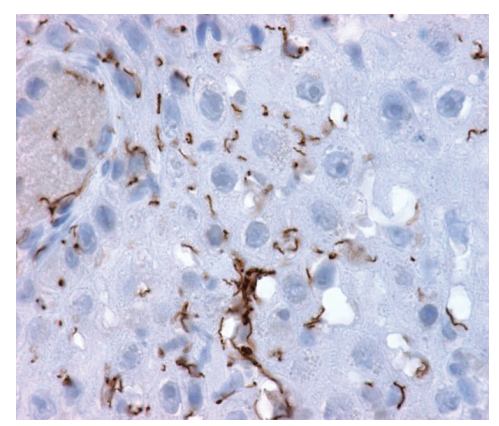

(c)

FIGURE 4: Secondary syphilis. H\&E stain $(4 \mathrm{x})$ shows a psoriasiform and lichenoid lymphoplasmacytic estomatitis with neutrophilic microabscesses in the stratum corneum (a), Warthin Starry stain (10x) shows a spirochete within the epithelium (dark small arrow) (b), and Treponema pallidum antibody (20x) shows multiple spirochetes within the epithelium (c).

On the other hand, we found four (20\%) papular cases, all accompanied with mucous patches and located on dorsal tongue, as it has been described by others $[15,16]$. The term papular refers to red, raised, firm round nodules with a grey center that may ulcerate [36]; in this respect, we found that nodular lesions were covered by a depapillated surface, as described by Dalmau et al. [15] and Baniandrés-Rodríguez et al. [16].

The diagnosis of oral secondary syphilis lesions, called the great imitator $[24,51]$, represents an important clinical challenge. In our report, erythematous candidosis was considered as the differential diagnosis in nine of macular and papular cases, and herpes simplex infection in two patients with shallow ulcers.

Oral lesions mimicking hairy leukoplakia (HL) or lichen planus (LP) were also observed in one patient each. It is important to explain that in order to confirm the diagnosis of oral syphilis, besides the positive serology test, a biopsy and histopathological analysis were performed to rule out HL and LP. Hairy leukoplakia and leukoplakia-like plaque have been considered in the differential diagnosis of recent case reports of secondary syphilis in HIV seronegative patients [24, 28, 31]. Remarkably, secondary syphilis mimicking pemphigus vulgaris-like oral lesions has been illustrated in a recent case report [22].

The definitive diagnosis of syphilis is based on clinical data and complemented with serological and pathological studies. It is important to emphasize that all cases were confirmed with a positive serological test and when possible with histopathological analysis. Demonstration of tissue spirochetes using silver stain (Warthin-Starry) can be difficult, nonspecific, and time consuming, whereas immunohistochemical technique to detect $T$. pallidum in tissue sections has proven to be sensitive and specific and may be very useful in formalin-fixed paraffin wax embedded tissues $[52,53]$.

The present study has certain limitations that need to be taken into account when considering the diagnosis of oral secondary syphilis: first, not all patients gave their consent to the biopsy procedure, and second, there is a lack of confirmatory FTA-ABS tests in five patients of one of the referral centers. However, all five patients had positive VDRL tests, also three had confirmatory histopathological studies and two presented oral mucous patches, which are considered the most typical oral manifestations of secondary syphilis. Also, in doubtful cases a biopsy was done.

Although clinical features (particularly in cases of mucous patches) are highly suggestive of secondary syphilis, VDRL is a nonspecific blood test, so the definitive diagnosis must be confirmed by tissue sample and/or FTA-ABS test. However, it must be considered in agreement with some authors $[12,13,54]$ that in secondary syphilis, VDRL is $100 \%$ sensitive and that the interpretation of treponemal and nontreponemal serological tests should be equivalent in HIVinfected and non-HIV-infected individuals. Also, in relation with sexual behavior only information about sex preference (MSM or heterosexual) was collected.

Our findings highlight that common oral diseases such as oral candidosis, intraoral human herpes virus infection, hairy leukoplakia, lichen planus, and other conditions considered by others such as lupus erythematosus, erythema multiforme, leukoplakia, erythroleukoplakia, squamous cell carcinoma, and nonspecific erosions should be included in the differential diagnosis of syphilis $[14,15,17,19,24,25,27,31]$.

\section{Conclusions}

Oral manifestations are frequent and protean in HIV-infected patients; lesions caused by syphilis may be easily mistaken for other common entities in these patients, so it is important to emphasize the role of a thorough oral examination in its early diagnosis.

Since syphilis is a treatable disease with a significant potential for serious complications if not treated, a missed diagnosis can have serious consequences for the patient. In routine care, especially in developing countries, accurate diagnostic tools are not always available, so physicians should be conscious that oral lesions could be the only evident clinical manifestation of a common but complex disease like syphilis.

Clinicians should be aware of the variable manifestations of the disease and the need to suspect it in the presence 
of oral lesions. Based on the present case series, dental and medical practitioners should consider secondary syphilis in the differential diagnosis of white, ulcerative, popular, and nodular oral lesions, particularly in HIV-infected patients.

\section{Conflict of Interests}

The authors declare that they have no conflict of interests. They do not have any financial and personal relationships with other people or organizations that could inappropriately influence their work.

\section{Acknowledgments}

The authors wish to express their appreciation to Dr. Jesús Casillas Rodríguez and Dr. Jehovanni González Arias for their participation and assistance on this collaborative study. Also, they express gratefulness to Dr. Isaac Van der Waal for his valuable comments after reading the paper.

\section{References}

[1] K. Buchacz, J. D. Klausner, P. R. Kerndt et al., "HIV incidence among men diagnosed with early syphilis in Atlanta, San Francisco, and Los Angeles, 2004 to 2005," Journal of Acquired Immune Deficiency Syndromes, vol. 47, no. 2, pp. 234-240, 2008.

[2] Centers for Disease Control and Prevention (CDC), Sexually Transmitted Disease Surveillance 2004 Supplement: Syphilis Surveillance Report, Department of Health and Human Services, Atlanta, Ga, USA, 2005.

[3] Centers for Disease Control and Prevention (CDC), "Primary and secondary syphilis-United States, 2003-2004," Morbidity and Mortality Weekly Report, vol. 55, no. 10, pp. 269-273, 2006.

[4] Centers for Disease Control and Prevention (CDC), Sexually Transmitted Disease Surveillance, 2008, U.S. Department of Health and Human Services, Atlanta, Ga, USA, 2009.

[5] A. Ganesan, A. Fieberg, B. K. Agan et al., "Results of a 25-year longitudinal analysis of the serologic incidence of syphilis in a cohort of HIV-infected patients with unrestricted access to care," Sexually Transmitted Diseases, vol. 39, no. 6, pp. 440-448, 2012.

[6] Centers for Disease Control and Prevention, Sexually Transmitted Disease Surveillance 2010, U.S. Department of Health and Human Services, Atlanta, Ga, USA, 2011.

[7] V. Bremer, U. Marcus, and O. Hamouda, "Syphilis on the rise again in Germany-results from surveillance data for 2011," Eurosurveillance, vol. 17, no. 29, p. 20222, 2012.

[8] D. Li, Y. Jia, Y. Ruan et al., "Correlates of incident infections for HIV, syphilis, and hepatitis B virus in A cohort of men who have sex with men in Beijing," AIDS Patient Care and STDs, vol. 24, no. 9, pp. 595-602, 2010.

[9] G. Karp, F. Schlaeffer, A. Jotkowitz, and K. Riesenberg, "Syphilis and HIV co-infection," European Journal of Internal Medicine, vol. 20, no. 1, pp. 9-13, 2009.

[10] N. M. Zetola and J. D. Klausner, "Syphilis and HIV infection: an update," Clinical Infectious Diseases, vol. 44, no. 9, pp. 1222-1228, 2007.

[11] G. Pialoux, S. Vimon, A. Moulignier, M. Buteux, B. Abraham, and P. Bonnard, "Effect of HIV infection on the course of syphilis," AIDS Reviews, vol. 10, no. 2, pp. 85-92, 2008.
[12] W. A. Lynn and S. Lightman, "Syphilis and HIV: a dangerous combination," Lancet Infectious Diseases, vol. 4, no. 7, pp. 456-466, 2004.

[13] N. M. Zetola, J. Engelman, T. P. Jensen, and J. D. Klausner, "Syphilis in the United States: an update for clinicians with an emphasis on HIV coinfection," Mayo Clinic Proceedings, vol. 82, no. 9, pp. 1091-1102, 2007.

[14] K. L. Ortega, N. P. M. Rezende, and M. H. C. G. Magalhães, "Diagnosing secondary syphilis in a patient with HIV," British Journal of Oral and Maxillofacial Surgery, vol. 47, no. 2, pp. 169-170, 2009.

[15] J. Dalmau, M. Alegre, M. A. Sambeat, E. Roé, L. Peramiquel, and A. Alomar, "Syphilitic nodules on the tongue," Journal of the American Academy of Dermatology, vol. 54, no. 2, pp. S59-S60, 2006.

[16] O. Baniandrés Rodríguez, O. Nieto Perea, L. Moya Alonso, R. Carrillo Gijón, and A. Harto Castaño, "Nodular secondary syphilis in a HIV patient mimicking cutaneous lymphoma," Anales de Medicina Interna, vol. 21, no. 5, pp. 241-243, 2004.

[17] K. L. Ortega, N. P. Rezende, F. Watanuki, N. Soares De Araujo, and M. H. C. G. Magalhaes, "Secondary syphilis in an HIV positive patient," Medicina Oral, vol. 9, no. 1, pp. 33-38, 2004.

[18] M. J. Romero-Jiménez, I. Suárez Lozano, J. M. Fajardo Picó, and B. Barón Franco, "Malignant syphilis in patient with human immunodeficiency virus (HIV): case report and literature review," Anales de Medicina Interna, vol. 20, no. 7, pp. 373-376, 2003.

[19] S. Y. Lu and H. L. Eng, "Secondary syphilis-related oral ulcers: report of four cases," Chang Gung Medical Journal, vol. 25, no. 10, pp. 683-688, 2002.

[20] R. Czerninski, A. Pikovski, K. Meir, N. Casap, A. E. Moses, and A. Maly, "Oral syphilis lesions-a diagnostic approach and histologic characteristics of secondary stage," Quintessence International, vol. 42, no. 10, pp. 883-889, 2011.

[21] K. Ikenberg, E. Springer, W. Bräuninger et al., "Oropharyngeal lesions and cervical lymphadenopathy: syphilis is a differential diagnosis that is still relevant," Journal of Clinical Pathology, vol. 63 , no. 8, pp. 731-736, 2010.

[22] M. D. Mignogna, G. Fortuna, S. Leuci, C. Mignogna, and M. Delfino, "Secondary syphilis mimicking pemphigus vulgaris," Journal of the European Academy of Dermatology and Venereology, vol. 23, no. 4, pp. 479-480, 2009.

[23] G. L. Murrell, "Secondary syphilis oral ulcer," OtolaryngologyHead and Neck Surgery, vol. 140, no. 6, pp. 942-943, 2009.

[24] D. Compilato, S. Amato, and G. Campisi, "Resurgence of syphilis: a diagnosis based on unusual oral mucosa lesions," Oral Surgery, Oral Medicine, Oral Pathology, Oral Radiology and Endodontology, vol. 108, no. 3, pp. e45-e49, 2009.

[25] M. Carlesimo, E. Palese, E. Mari et al., "Isolated oral erosions: an unusual manifestation of secondary syphilis," Dermatology Online Journal, vol. 14, no. 2, p. 23, 2008.

[26] M. Hayes, D. White, and A. Richards, "Secondary syphilis presenting as atypical oral ulceration-a case report," Dental Update, vol. 35, no. 7, pp. 465-467, 2008.

[27] J. E. Herrero-gonzález, M. E. P. Amer, M. F. Farrés, A. T. Abelló, C. Barranco, and R. M. Pujol, "Syphilitic mucous patches: the resurgence of an old classic," International Journal of Dermatology, vol. 47, no. 12, pp. 1281-1283, 2008.

[28] A. Stepanova and W. C. Marsch, "Plaques opalines. A rare form of secondary syphilis of the oral mucous membrane," Hautarzt, vol. 57, no. 6, pp. 514-517, 2006. 
[29] H. Hua, Z. M. Yan, R. T. Shi, Y. Gao, and Y. Y. Xu, "Clinical and pathological analysis of oral manifestations of 40 patients with secondary syphilis," Zhonghua Kou Qiang Yi Xue Za Zhi, vol. 40, no. 5, pp. 376-378, 2005.

[30] A. Paz and I. Potasman, "Oral lesions as the sole presenting symptom of secondary syphilis," Travel Medicine and Infectious Disease, vol. 2, no. 1, pp. 37-39, 2004.

[31] C. Aquilina, R. Viraben, and P. Denis, "Secondary syphilis simulating oral hairy leukoplakia," Journal of the American Academy of Dermatology, vol. 49, no. 4, pp. 749-751, 2003.

[32] A. Christen, H. E. Killer, B. Stamm, and P. Itin, "Secundary syphilis with ocular manifestation and oral ulceration," Schweizerische Rundschau fur Medizin-Praxis, vol. 92, no. 9, pp. 397-402, 2003.

[33] S. Dave, D. V. Gopinath, and D. M. Thappa, "Nodular secondary syphilis," Dermatology Online Journal, vol. 9, no. 1, p. 9, 2003.

[34] A. Ulmer and G. Fierlbeck, "Images in clinical medicine. Oral manifestations of secondary syphilis," The New England Journal of Medicine, vol. 347, no. 21, p. 1677, 2002.

[35] G. Ficarra and R. Carlos, "Syphilis: the renaissance of an old disease with oral implications," Head and Neck Pathology, vol. 3, no. 3, pp. 195-206, 2009.

[36] J. C. Leão, L. A. Gueiros, and S. R. Porter, "Oral manifestations of syphilis," Clinics, vol. 61, no. 2, pp. 161-166, 2006.

[37] E. Schneider, S. Whitmore, K. M. Glynn, K. Dominguez, A. Mitsch, and M. T. McKenna, "Revised surveillance case definitions for HIV infection among adults, adolescents, and children aged $<18$ months and for HIV infection and AIDS among children aged 18 months to $<13$ years-United States, 2008," Morbidity and Mortality Weekly Report, vol. 57, no. 10, pp. 1-12, 2008.

[38] R. Adolf, F. Bercht, M. L. Aronis, L. W. Lunardi, M. Schechter, and E. Sprinz, "Prevalence and risk factors associated with syphilis in a cohort of HIV positive individuals in Brazil," AIDS Care, vol. 24, pp. 252-258, 2012.

[39] M. C. Thurnheer, R. Weber, L. Toutous-Trellu et al., "Occurrence, risk factors, diagnosis and treatment of syphilis in the prospective observational Swiss HIV Cohort Study," AIDS, vol. 24, no. 12, pp. 1907-1916, 2010.

[40] E. P. Chow, D. P. Wilson, and L. Zhang, "HIV and syphilis co-infection increasing among men who have sex with men in China: a systematic review and meta-analysis," PLoS One, vol. 6, no. 8, Article ID e22768, 2011.

[41] E. Muldoon and F. Mulcahy, "Syphilis resurgence in Dublin, Ireland," International Journal of STD \& AIDS, vol. 22, no. 9, pp. 493-497, 2011.

[42] P. Pathela, S. L. Braunstein, J. A. Schillinger, C. Shepard, M. Sweeney, and S. Blank, "Men who have sex with men have a 140-fold higher risk for newly diagnosed HIV and syphilis compared with heterosexual men in New York City," JAIDS Journal of Acquired Immune Deficiency Syndromes, vol. 58, no. 4, pp. 408-416, 2011.

[43] W. Jarzebowski, E. Caumes, N. Dupin et al., "Effect of early syphilis infection on plasma viral load and CD4 cell count in human immunodeficiency virus-infected men: results from the FHDH-ANRS CO4 cohort," Archives of Internal Medicine, vol. 172, no. 16, pp. 1237-1243, 2012.

[44] A. C. Weintrob, W. Gu, J. Qin et al., "Syphilis co-infection does not affect HIV disease progression," International Journal of STD and AIDS, vol. 21, no. 1, pp. 57-59, 2010.
[45] R. Palacios, F. Jiménez-Oñate, M. Aguilar et al., "Impact of syphilis infection on HIV viral load and CD4 cell counts in HIV-infected patients," Journal of Acquired Immune Deficiency Syndromes, vol. 44, no. 3, pp. 356-359, 2007.

[46] K. Kofoed, J. Gerstoft, L. R. Mathiesen, and T. Benfield, "Syphilis and human immunodeficiency virus (HIV)-1 coinfection: influence on CD4 T-cell count, HIV-1 viral load, and treatment response," Sexually Transmitted Diseases, vol. 33, no. 3, pp. 143-148, 2006.

[47] K. Buchacz, P. Patel, M. Taylor et al., "Syphilis increases HIV viral load and decreases CD4 cell counts in HIV-infected patients with new syphilis infections," AIDS, vol. 18, no. 15, pp. 2075-2079, 2004.

[48] V. Ramirez-Amador, J. G. Sierra Madero, L. E. Pedraza et al., "Oral secondary syphilis in a patient with human immunodeficiency virus infection," Oral Surgery, Oral Medicine, Oral Pathology, Oral Radiology, and Endodontics, vol. 81, no. 6, pp. 652-654, 1996.

[49] G. Ficarra, A. M. Zaragoza, L. Stendardi, F. Parri, and C. J. Cockerell, "Early oral presentation of lues maligna in a patient with HIV infection: a case report," Oral Surgery Oral Medicine and Oral Pathology, vol. 75, no. 6, pp. 728-732, 1993.

[50] A. J. Bruce and R. S. Rogers, "Oral manifestations of sexually transmitted diseases," Clinics in Dermatology, vol. 22, no. 6, pp. 520-527, 2004.

[51] G. P. Domantay-Apostol, E. B. Handog, and M. T. G. Gabriel, "Syphilis: the international challenge of the great imitator," Dermatologic Clinics, vol. 26, no. 2, pp. 191-202, 2008.

[52] M. Buffet, P. A. Grange, P. Gerhardt et al., "Diagnosing Treponema pallidum in secondary syphilis by PCR and immunohistochemistry," Journal of Investigative Dermatology, vol. 127, no. 10, pp. 2345-2350, 2007.

[53] A. W. Barrett, M. V. Dorrego, T. A. Hodgson et al., "The histopathology of syphilis of the oral mucosa," Journal of Oral Pathology and Medicine, vol. 33, no. 5, pp. 286-291, 2004.

[54] D. Daskalakis, "Syphilis: continuing public health and diagnostic challenges," Current HIV/AIDS Reports, vol. 5, no. 2, pp. 72-77, 2008. 


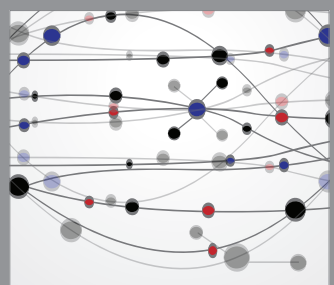

The Scientific World Journal
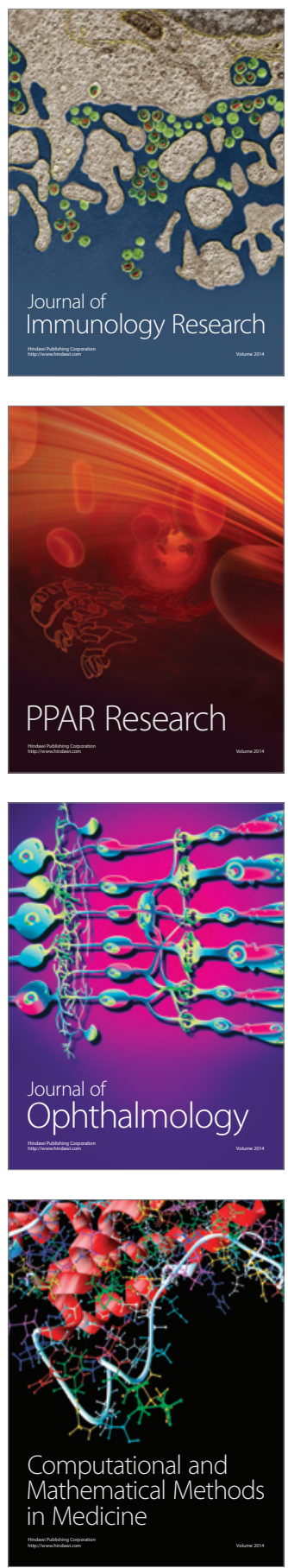

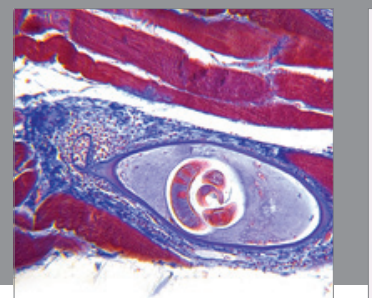

Gastroenterology

Research and Practice
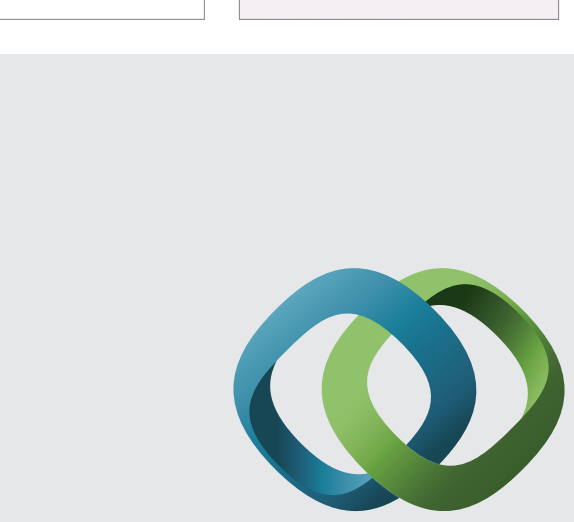

\section{Hindawi}

Submit your manuscripts at

http://www.hindawi.com
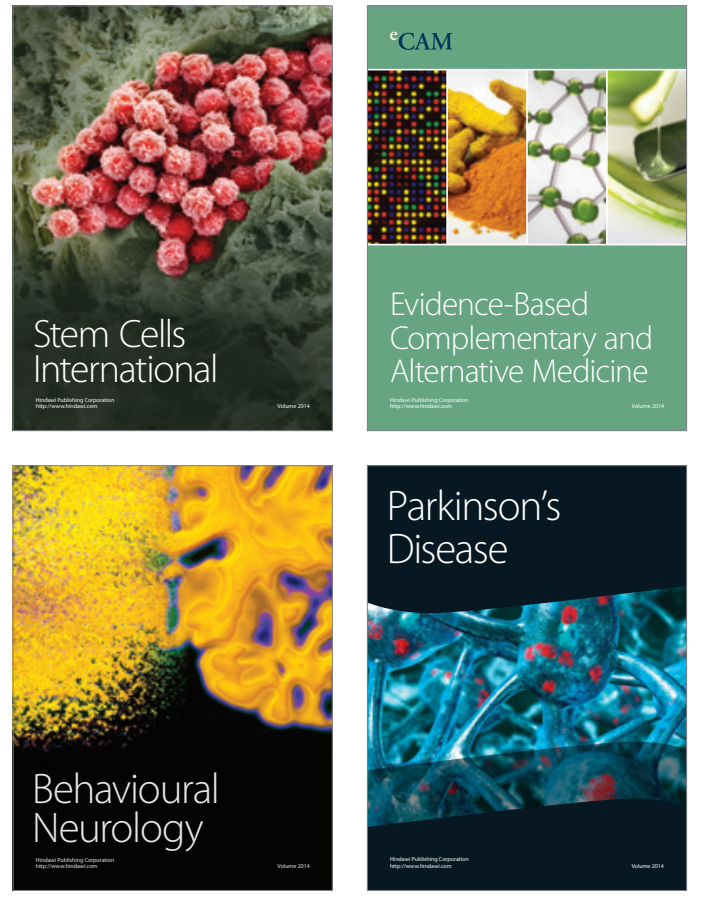
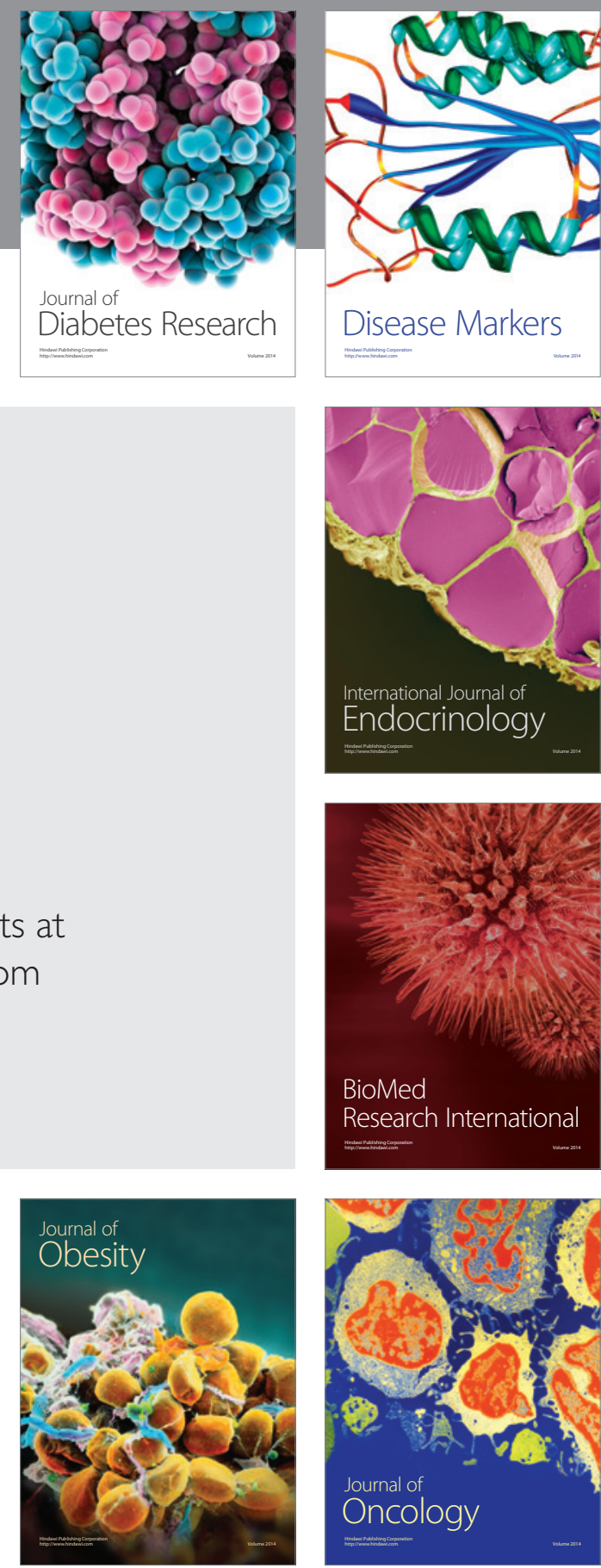

Disease Markers
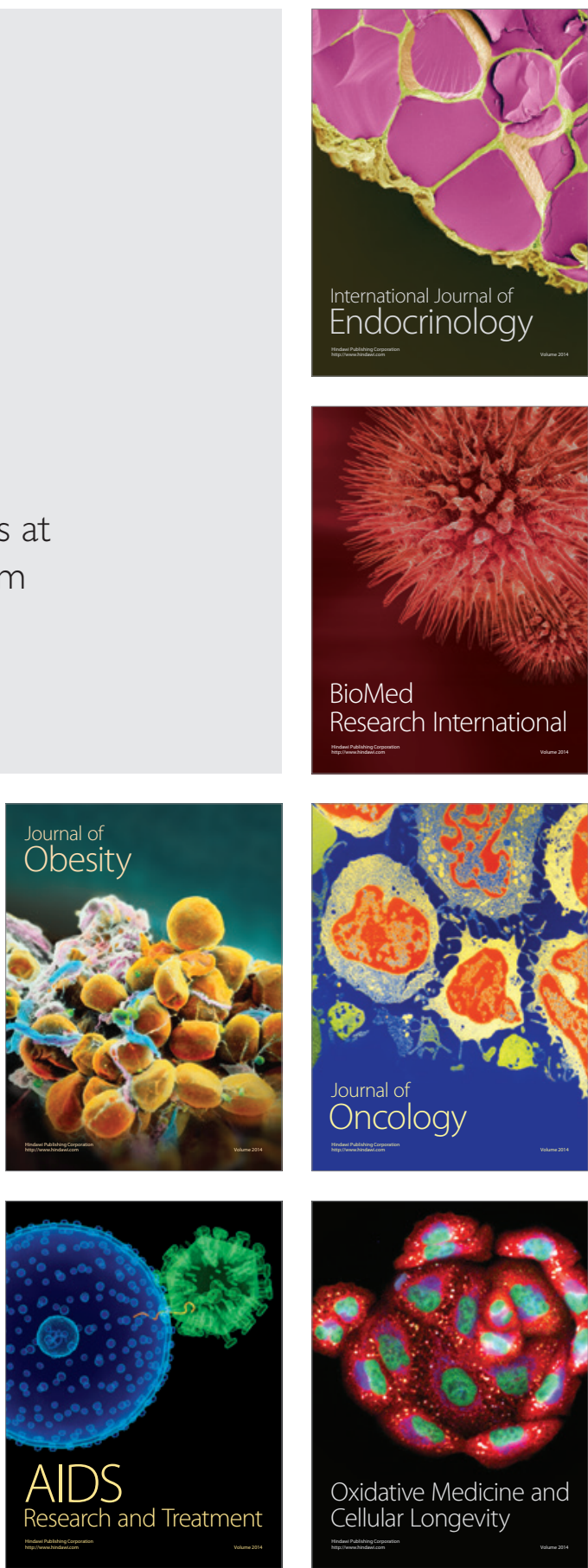